\title{
LA CONCENTRACIÓN DE LOS MEDIOS DE COMUNICACIÓN Y LOS ALCANCES DEL SEGUNDO PÁRRAFO DEL ARTÍCULO 61 DE LA CoNSTITUCIÓN PERUANA EN LA PRENSA ESCRITA The Scope of the Second Paragraph of Article 61 of Peru's Constitution in the Written Press
}

\section{Bruno Adriano Delgado Taboada}

Pontificia Universidad Católica del Perú, Perú

Bachiller por la Facultad de Derecho de la Pontificia Universidad Católica del Perú y candidato al Título de segunda especialidad en Derecho Público y Buen Gobierno por la misma casa de estudios. bruno.1dt@ gmail.com.

\section{RESUMEN}

La concentración de los medios de comunicación es un fenómeno que se ha extendido por todo el mundo poniendo en peligro el derecho de los ciudadanos a acceder a información diversa y plural. El presente artículo circunscribe su objeto de estudio al análisis de los alcances del segundo párrafo del artículo 61 de la Constitución peruana respecto de la concentración de los medios de comunicación en general y, en especial, concentraciones en prensa escrita. En ese sentido se elabora un análisis mixto, tanto de fuentes de derecho como de doctrina nacional e internacional. Finalmente se plantea la pregunta acerca de cuál alternativa es la mejor opción frente a la concentración mediática: regulación o judicialización.

\section{Palabras clave}

Concentración de medios de comunicación; libertades de expresión e información; pluralismo informativo; prensa escrita.

\section{Abstract}

The concentration of media ownership is a phenomenon that has expanded all over the world, jeopardizing the rights of citizens to access information that is both diverse and pluralistic. This paper analyses the scope of the second paragraph of Article 61 of the Peruvian Constitution, as it pertains to the concentration of media ownership in general and, in particular, the consolidation of the written press. To this end, it is carried out a mixed analysis, including sources of national and international law and doctrine. Finally, it is discussed which is the better alternative in the face of media consolidation, regulation or prosecution.

\section{KEY WORDS}

Concentration of media; freedom of expression and of information; pluralism of information; written press. 
Bruno Adriano Delgado Taboada

La concentración de los medios de comunicación y los alcances del segundo párrafo del artículo 61 de la Constitución peruana en la prensa escrita

\section{INTRODUCCIÓN: LA CONCENTRACIÓN MEDIÁTICA COMO PROBLEMA en el Perú y en el MUNdo}

La concentración de los medios de comunicación es un fenómeno global y uno de los problemas jurídicos más trascendentes del siglo XXI. Es de vital importancia para la defensa del Estado constitucional de derecho que se desarrollen los mecanismos institucionales que impidan el control de los medios de comunicación por parte del Estado o de los privados. Los peligros para el sistema democrático no solo se miden respecto del pluralismo informativo, sino que los medios también definen la agenda pública de qué se discute y a qué se le toma importancia en los países en que ejercen influencia.

Asimismo, la problemática jurídica resulta muy compleja y ha derivado en un debate entre dos posturas respecto de la pertinencia de la regulación vigente en el Perú. La primera sostiene que la concentración mediática en prensa escrita no constituye en sí misma un problema y que, además, la intervención del Estado legislando o regulando esta materia supondría un riesgo para la libertad de expresión, y la segunda sustenta que toda concentración mediática excesiva es en sí misma un atentado contra la democracia y contra el pluralismo informativo, por lo que es necesario regular esta materia.

Hasta el momento, la discusión ha girado en torno a posiciones sobre el "deber ser" y no se ha analizado cuáles son los alcances jurídicos del artículo 61 de la Constitución como normativa vigente. Es por ello de vital importancia que se estudie el contenido jurídico del artículo constitucional en cuestión y sus alcances.

Finalmente, la confrontación entre ambas posturas se ha materializado en una demanda de amparo interpuesta por un conjunto de periodistas contra el grupo El Comercio por la adquisición de Epensa en el Perú. La judicialización de este conflicto es, así, una evidente consecuencia de la insuficiencia de la regulación vigente para resolver el problema. Consecuentemente, resulta importante preguntarnos si la judicialización es la respuesta idónea para solucionar este conflicto o si, por el contrario, la judicialización es la única salida hasta el momento pero no la mejor.

\section{El CONTENIDO JURídico DEL PLURALISMO INFORMATIVo}

Hay un relativo consenso en la doctrina internacional, como veremos más adelante, respecto del contenido jurídico del pluralismo informativo. Así pues, hay claridad acerca de qué elementos contiene el pluralismo informativo y respecto de qué situaciones deberán impedirse en aras de garantizar su observancia.

Podemos hablar de dos dimensiones complementarias del pluralismo informativo: el pluralismo informativo externo e interno ${ }^{1}$. El pluralismo informativo externo supone la creación de un sistema que garantice la libre concurrencia de información plural y, de este modo, disciplinar la concentración de los medios de comunicación, sometiéndolos a un control democrático ${ }^{2}$. Por otro lado, el pluralismo informativo interno supone la garantía de que, en el interior de los medios de comunicación, se exprese una diversidad

1 Lovatón Palacios, David (2014). "El equilibrio interamericano entre la pluralidad de información y concentración de medios". Revista Derecho PUCP (73): 140.

2 Rodríguez, José (1998). El control de los medios de comunicación. Madrid: Editorial Dykinson, pp. 7-8. 
de opiniones políticas ${ }^{3}$. Al respecto, hay múltiples autores que coinciden en que el contenido jurídico del pluralismo informativo comprende una dimensión interna y externa ${ }^{4}$.

Si bien es cierto que el contenido jurídico del pluralismo informativo se puede resumir en los elementos antes descritos, existen posturas que plantean un margen de protección más amplio. Así pues, hay autores que plantean que el pluralismo informativo debería extenderse a los siguientes aspectos: (i) libertad del profesional informador, (ii) diversidad de medios de comunicación, (iii) pluralidad social en la información y (iv) tratamiento objetivo e imparcial de la información ${ }^{5}$. No obstante, la posición aceptada universalmente es la que distingue el pluralismo informativo externo del pluralismo informativo interno.

Ahora bien, sabiendo cuál es el contenido jurídico del pluralismo informativo, es factible preguntarnos: ¿qué medidas públicas corresponden a cada tipo de pluralismo informativo? Pues, la mejor forma de clarificar la diferencia entre ambos es plantear ejemplos. En el caso del Perú, un buen ejemplo de medida que busca tutelar el pluralismo informativo externo es la existencia de cuotas límite de mercado que se pueden adquirir en radio ( $20 \%$ del mercado) y televisión ( $30 \%$ del mercado), reguladas en la Ley de Radio y Televisión ${ }^{6}$. Por otro lado, un buen ejemplo de medida que tiene por objeto tutelar el pluralismo informativo interno es la franja electoral, regulada en la Ley de Partidos Políticos ${ }^{7}$ de la República del Perú.

\section{La regulación de la concentración de la Prensa escrita en el Perú}

La única norma en el ordenamiento jurídico peruano que regula la concentración de medios en prensa escrita es el segundo párrafo del artículo 61 de la Constitución de 1993:

"La prensa, la radio, la televisión y los demás medios de expresión y comunicación social; y, en general, las empresas, los bienes y servicios relacionados

3 Llamazares, María (1999). Las libertades de expresión e información como garantía del pluralismo democrático. Madrid: Editorial Civitas Ediciones, p. 146.

4 Véase, por ejemplo, Lovatón Palacios, David (2016). "Estándares interamericanos sobre pluralidad de información y concentración de medios”. En: KRESALJA, Baldoy David Lovatón (coords.), ¿Puede acapararse la libertad? Libertad de expresión y concentración de medios en el Perú. Lima: Oficina Académica de Publicaciones, Comunicación e Imagen de la Facultad de Derecho de la Pontificia Universidad Católica del Perú, p. 107; Rodríguez, José (1998). El control de los medios de comunicación. Madrid: Editorial Dykinson, pp. 7-8; Llamazares, María (1999). Las libertades de expresión e información como garantía del pluralismo democrático. Madrid: Editorial Civitas Ediciones, p. 146; Dodds Berger, Daniel (2011). "Concentración de medios y libertad de comunicación. Un análisis jurídico-constitucional”. Repositorio Académico de la Universidad de Chile. Disponible en: <http://www.repositorio.uchile.cl/handle/2250/111866> [consulta: 25 mayo 2015]; ZúÑIGA, Francisco (2008). "Propiedad y control de los medios de comunicación social: algunas notas sobre el estatuto de radiodifusión”. Revista Estudios Constitucionales 6(1): 172-173; FARFÁn, Ronnie (2014). "La prohibición constitucional de concentración de la propiedad de los medios de comunicación”. Revista de Derecho Administrativo (14): 352; Gómez, Alberto (2002). El control de las concentraciones de medios de comunicación. Madrid: Editorial Dykinson, p. 35.

5 Rallo, Artemi (2000). Pluralismo informativo y constitución. Valencia: Editorial Tirant lo Blanch, pp. 41-60.

6 Ley N 28278 de 2004 por la cual se aprueba la Ley de Radio y Televisión. Congreso de la República del Perú, 16 de julio de 2004.

7 Ley N 28094 de 2003 por la cual se aprueba la Ley de Partidos Políticos. Congreso de la República del Perú, 1 de noviembre de 2003. 
Bruno Adriano Delgado Taboada

La concentración de los medios de comunicación y los alcances del segundo párrafo del artículo 61 de la Constitución peruana en la prensa escrita

con la libertad de expresión y de comunicación, no pueden ser objeto de exclusividad, monopolio ni acaparamiento, directa ni indirectamente, por parte del Estado ni de particulares"8.

Ahora bien, el origen de esta norma está en el artículo 134 de la Constitución de 1979², el que es idéntico a su sucesor: el segundo párrafo del artículo 61 de la Constitución de 1993. Los comentarios de los juristas respecto del referido artículo 134 de la Constitución de 1979 reflejan posiciones similares. Ruiz-Eldredge sostiene que el referido artículo debe interpretarse haciendo hincapié en la participación y acceso de los ciudadanos a un auténtico flujo de información libre ${ }^{10}$; en esa misma línea tenemos la interpretación de Marcial Rubio y Enrique Bernales, quienes señalan que existe una vinculación especial entre el derecho a las libertades de información, opinión, expresión y difusión del pensamiento, reguladas en el artículo $2^{\circ}$ inciso 4 de la Constitución de 1979, y la prohibición del artículo $134^{11}$ de la Constitución de 1979. No obstante, todos los autores sostienen que, en lo que a concentración mediática se refiere, el artículo 134 carecería de contenido propio suficiente para ser algo más que una declaración de principios ${ }^{12}{ }^{13}$.

En la doctrina peruana contemporánea existe mayor controversia al respecto. Actualmente hay dos posiciones manifiestamente distintas: la primera sostiene que de esta disposición se desprende un mandato constitucional de evitar la concentración de los medios de comunicación, por razones similares a las de los juristas que comentaron el artículo 134 de la Constitución de $1979^{14}$, y la segunda sostiene que debido al avance tecnológico de las comunicaciones y del internet la interpretación de este artículo debería ser restringida, en tanto la justificación inicial que tuvo esta norma ya no se condice con la realidad $^{15}$. Es interesante destacar especialmente la posición de Beaumont Callirgos,

8 Constitución Política del Perú de 1993. Congreso Constituyente Democrático de la República del Perú, 30 de diciembre de 1993.

9 Constitución Política del Perú de 1979. Asamblea Constituyente de la República del Perú, 13 de agosto de 1980 .

10 Ruiz-Eldredge, Alberto (1980). La Constitución comentada 1979. Lima: Editorial Atlántida, pp. 223-224.

11 Rubio, Marcial y Enrique Bernales (1983). Constitución y sociedad política. Lima: Editorial Mesa Redonda Editores, pp. 108-109.

12 Rubio y Bernales (1983): 121-125.

13 Es factible destacar que en la ya citada La Constitución Comentada 1979 de Ruiz-Eldredge se hace referencia a que el artículo $134^{\circ}$ tiene alcances respecto de la radio, la televisión y, también, la prensa escrita. RUIZ-ELDREDGE (1980): 223-224.

14 Véanse, por ejemplo, Rubio, Marcial (2015). Para conocer la Constitución de 1993. Lima: Fondo Editorial PUCP, pp. 131-132; LANDa, César (2015). La inconstitucionalidad de la concentración de la prensa escrita. Lima: Portal Jurídico IUS $360^{\circ}$. Disponible en: <http://www.ius360.com/publico/constitucional/ la-inconstitucionalidad-de-la-concentracion-de-la-prensa-escrita/> [consulta: 15.05.2015]; RoJAs, Juan Francisco (2013). "Promoción de la competencia y prohibición de monopolios". En: Chanamé, Raúl (ed.). La Constitución Comentada. Tomo II. Lima: Editorial Gaceta Jurídica, pp. 88-97; Beaumont Callirgos, Ricardo (2013). "Monopolios y medios de comunicación social". En: Chanamé, Raúl (ed.), La Constitución Comentada. Tomo II, Lima: Editorial Gaceta Jurídica, pp. 98-103; LANDA, César (2016). "El artículo 61 de la Constitución y la concentración de los medios de comunicación”. En: KRESALJA, Baldo y David Lovatón (coords.). ¿̇Puede acapararse la libertad? Libertad de expresión y concentración de medios en el Perú. Lima: Oficina Académica de Publicaciones, Comunicación e Imagen de la Facultad de Derecho de la Pontificia Universidad Católica del Perú, pp. 341-375.

15 Bullard, Alfredo (2013). "Regulación constitucional de los monopolios y protección de la Libre Competencia". En: Chanamé, Raúl (ed.). La Constitución Comentada. Tomo II. Lima: Editorial Gaceta Jurídica, 
quien defiende que el segundo párrafo del artículo $61^{\circ}$ prohíbe la sola concentración directa o indirecta de los medios de comunicación en aras de proteger el pluralismo informativo ${ }^{16}$ que funge como garantía del sistema democrático.

Particularmente, consideramos que la interpretación más acertada sería la primera: según esta, estamos ante una prohibición o restricción constitucional que tiene la finalidad de resguardar el derecho fundamental a la libertad de información y a la libertad de expresión, o a ambos, que se manifiesta en un bien jurídico constitucionalmente protegido llamado pluralismo informativo. Esta posición es similar a la que mantiene Landa, quien incluso va más allá y señala que puede decirse que el pluralismo informativo es en sí mismo un derecho fundamental ${ }^{17}$. Incluso, el mismo Tribunal Constitucional (TC) señala que el segundo párrafo del artículo 61 de la Constitución impone al Estado el deber de promover el pluralismo informativo ${ }^{18}$.

Entonces, tenemos claro los derechos y bienes jurídicos que busca proteger el segundo párrafo del artículo 61 de la Constitución, también los ámbitos en los que tiene alcance: prensa, radio, televisión y demás medios de comunicación social. Sin embargo, ¿el segundo párrafo del artículo 61 puede por sí mismo cumplir su finalidad? Consideramos que no, pues requiere necesariamente de un desarrollo legislativo que le permita ser algo más que una declaración de principios. Es por este motivo que se aprobó la Ley No 28.278 -Ley de Radio y Televisión (LRT)-, en donde se intentó desarrollar el contenido de la referida norma constitucional.

Sin embargo, la LRT no soluciona el problema de la concentración mediática y, a nuestro juicio, incurre en graves errores y omisiones, tanto en su formulación como en su interpretación constitucional. El artículo 22 de la LRT reformula la disposición constitucional del segundo párrafo del artículo 61 limitándose únicamente a frecuencias de radio y televisión y excluyendo a la prensa y demás medios de comunicación social. Además, el referido artículo 22 menciona que para efectos de esa ley se considerará acaparamiento que una persona natural o jurídica posea directa o indirectamente más del 30\% de las frecuencias disponibles en radiodifusión televisiva y más del 20\% en radiodifusión sonora. No obstante, dicha ley, a pesar de estar formulada aparentemente con buenas intenciones, confunde escenarios manifiestamente distintos y pretende ser concebida como el desarrollo legislativo de una disposición constitucional con cuyo contenido no tiene relación.

pp. 69-87; Northcote Sandoval, Cristhian (2014). "La supuesta concentración de medios en la prensa escrita”. Revista Actualidad Empresarial (294): 1-4. Disponible en: <http://aempresarial.com/servicios/ revista/294_43_OUYGHCWQSUHXCBZNUSGFVLFDQQRZDJIREGXLJTCCOKZQLYEGQK.pdf> [consulta: 25.05.2015]; TAVERA, José (2014). "Acerca de la concentración de la propiedad de los medios de comunicación". Portal Jurídico IUS $360^{\circ}$, Lima. Disponible en: <http://www.ius360.com/publico/ administrativo/acerca-de-las-concentracion-de-propiedad-en-los-medios-de-comunicacion/> [consulta: 25.05.2015]; BULLARD, 2016: 501-573.

16 Beaumont, 2013: 98-103.

17 LANDA, César (2015). La inconstitucionalidad de la concentración de la prensa escrita. Lima: Portal Jurídico IUS $360^{\circ}$. Disponible en: <http://www.ius360.com/publico/constitucional/la-inconstitucionalidad-de-laconcentracion-de-la-prensa-escrita/> [consulta: 15.05.2015].

18 Tribunal Constitucional de la República del Perú. Sentencia recaída en el Expediente No 00013-2007-AI/ TC. Sentencia de 13 de julio de 2007, párr. 18. 
Bruno Adriano Delgado Taboada

La concentración de los medios de comunicación y los alcances del segundo párrafo del artículo 61 de la Constitución peruana en la prensa escrita

La LRT no es idónea para desarrollar legislativamente el segundo párrafo del artículo $61^{\circ}$ de la Constitución por tres motivos. En primer lugar, restringe los alcances del mandato constitucional y no se desprende de ella ninguna razón que justifique que una ley limite la aplicación de la disposición constitucional que pretende desarrollar. En segundo lugar, la ley no cumple idóneamente con solucionar el problema de la concentración de medios, pues no solo excluye uno de los supuestos sino que omite regular la más peligrosa de las concentraciones: la propiedad cruzada de medios de comunicación; y, por si fuera poco, utiliza un sistema de cuotas tope de frecuencias para impedir la concentración, pero no regula ni prohíbe los actos de concentración en sí mismos, condenándose a quedar obsoleta frente a las nuevas tecnologías que no dependen del uso del espacio radioeléctrico. En tercer lugar, la LRT en realidad se encuentra desarrollando el artículo $66^{\circ}$ de la Constitución, referido a los recursos naturales de la nación; esto es así, en tanto el objeto de la ley es la regulación del otorgamiento en concesión del espacio radioeléctrico como recurso natural y no la defensa del pluralismo informativo.

Es admisible hacer especial énfasis en la especial peligrosidad que la propiedad cruzada de medios de comunicación puede tener en el pluralismo informativo, por cuanto, como lo señala Kresalja, aquella "es contraria a lograr el pluralismo informativo, agravado si quien la tiene, además, ostenta una indiscutida posición dominante y absorbe porcentajes muy altos de publicidad frente a otros competidores. Tratar y superar este tema es de más alta prioridad"19. Asimismo, el impacto que la concentración cruzada de medios de comunicación puede tener en el pluralismo informativo es de especial relevancia desde el enfoque de la teoría de la agenda setting, en donde el verdadero poder de los medios de comunicación radica en determinar a qué temas se les da importancia en la esfera pública y a cuáles no ${ }^{20}$. En ese sentido, la concentración cruzada resulta especialmente peligrosa, en la medida en que esta facilita la dirección de la agenda pública desde múltiples medios de comunicación de forma concertada. Es por este motivo que el TC puso especial énfasis en la omisión del legislador de prohibir la concentración cruzada en la LRT ${ }^{21}$.

Ahora bien, la LRT ha sido ampliamente debatida y es una de las leyes más cuestionadas por acciones de inconstitucionalidad en los últimos años, estas han permitido que el TC se haya pronunciado por el contenido de esta norma. Con la sentencia recaída en el Expediente $\mathrm{N}^{\mathrm{o}}$ 00013-2007-AI/TC, el TC resolvió el cuestionamiento al artículo 24 de la LRT, determinando que la disposición que impedía a los extranjeros poseer más del 40\% de las acciones en empresas de medios de comunicación era inconstitucional por ser discriminatoria ${ }^{22}$. Asimismo, mediante la sentencia recaída en el Expediente $\mathrm{N}^{\mathrm{o}}$ 00015-2010-AI/TC, el TC resolvió el cuestionamiento al artículo 22 de la misma

19 Kresalja, Baldo (2016). "Nadie puede negar”. En: Kresalja, Baldo y David Lovatón (coords.). ¿Puede acapararse la libertad? Libertad de expresión y concentración de medios en el Perú. Lima: Oficina Académica de Publicaciones, Comunicación e Imagen de la Facultad de Derecho de la Pontificia Universidad Católica del Perú, pp. 423-424.

20 ZuKernik, Eduardo (2008). Observador de medios de comunicación en América Latina: prensa, ciudadanía y democracia en Brasil, Colombia, Ecuador, Perú y Venezuela. Primera edición. Buenos Aires: Konrad Adenauer Stiftung, p. 162.

21 Tribunal Constitucional de la República del Perú. Sentencia recaída en el Expediente Nº 00013-2007-AI/ TC, párr. 15.

22 Tribunal Constitucional de la República del Perú. Expediente No 00013-2007-AI/TC., párrs. 27 al 30. 
ley, determinando que la disposición que establece diferenciaciones entre las cuotas máximas de frecuencias de radio y televisión es constitucional ${ }^{23}$.

El TC aprovechó estas dos oportunidades para establecer postura acerca del contenido de la ley y para desarrollar aspectos constitucionales vinculados a la misma. Así pues, mediante la primera sentencia, el TC desarrolla su posición respecto de la diferenciación entre el derecho a la libertad de expresión y el derecho a la libertad informativa; asimismo, entre otras consideraciones referidas a la sujeción de las empresas de radio y televisión a los principios recogidos por la norma, se determina en el fundamento 18 que del segundo párrafo del artículo 61 se desprende un mandato constitucional de promover un verdadero pluralismo informativo. Por otro lado, mediante la segunda sentencia, el TC reitera la existencia de un mandato constitucional de promover y garantizar el pluralismo informativo; además, determina que este bien constitucionalmente protegido es una condición indispensable para el desarrollo de una sociedad democrática sentenciando: "no existe democracia sin pluralismo"24. Finalmente, el TC indica que la prohibición a los monopolios respecto de medios de comunicación no requiere mayor desarrollo legal, pero respecto del acaparamiento se pregunta: " ¿Con el control de cuánto porcentaje del total de medios de comunicación una persona 'acapara' el mercado de medios?"25. Así, pues, el TC responde lo siguiente:

"Desde luego, no existe un solo modo constitucionalmente válido de regular legalmente la prohibición prevista en el artículo 61 de la Norma Fundamental. Mientras se cumpla con el objetivo constitucionalmente trazado, a saber, que el Estado o los particulares no acaparen el control sobre los medios de comunicación, el legislador, en ejercicio del principio de libre configuración legal (artículo 93 de la Constitución), puede optar por distintas fórmulas que resulten idóneas para conseguirlo" 26 .

De este modo, el TC ha determinado que la LRT sí desarrolla en cierto sentido el segundo párrafo del artículo $61^{\circ}$ y la vincula con la protección del pluralismo informativo. No obstante, mediante el fundamento 29 , que acabamos de citar, el TC señala que no se han agotado las posibilidades de regular legalmente la prohibición prevista en el segundo párrafo del artículo 61 de la Constitución y que se podrá optar por distintas fórmulas que resulten idóneas para conseguir prevenir el acaparamiento.

En ese sentido, podemos decir que, en materia de leyes que desarrollen el segundo párrafo del artículo 61, para efectos de resguardar el pluralismo informativo ante actos de concentración mediática, estamos frente a un vacío legal por cuanto el Estado peruano no ha implementado ninguna medida para evitar el acaparamiento de los medios ${ }^{27}$ más allá de la LRT. No hay desarrollo jurisprudencial o legal suficiente

23 Tribunal Constitucional de la República del Perú. Expediente Nº 00015-2010-Ai/TC. Sentencia de 11 de septiembre de 2012, párr. 43.

24 Tribunal Constitucional de la República del Perú. Expediente No 00015-2010-AI/TC, párr. 20.

25 Tribunal Constitucional de la República del Perú. Expediente No 00015-2010-Ai/TC, párr. 28.

26 Tribunal Constitucional de la República del Perú. Expediente No 00015-2010-AI/TC, párr. 29.

27 TÁvara, José (2016). "Economía Política de la concentración de los medios". En: Kresalja, Baldo y David LOVATón (coords.). ¿Puede acapararse la libertad? Libertad de expresión y concentración de medios en el Perú. Lima: Oficina Académica de Publicaciones, Comunicación e Imagen de la Facultad de Derecho de la Pontificia Universidad Católica del Perú, p. 434. 
Bruno Adriano Delgado Taboada

La concentración de los medios de comunicación y los alcances del segundo párrafo del artículo 61 de la Constitución peruana en la prensa escrita

que nos permita interpretar cuál es el significado del término acaparamiento y a qué supuestos alcanza el contenido del referido artículo constitucional en prensa escrita, como señala Kresalja ${ }^{28}$. Al respecto, Landa refiere que "el concepto de 'concentración y/o acaparamiento de medios' no es unívoco"29; asimismo, a pesar de las dificultades para precisar el término y del vacío legal respecto de la prensa escrita, argumenta que debe entenderse que la Constitución prohíbe tanto el acaparamiento como la concentración de la prensa escrita ${ }^{30}$. Sin embargo, hay autores, como Bullard, que afirman que la LRT ya cerró la discusión relativa a la interpretación del término acaparamiento, en tanto la exclusión de la prensa escrita en la ley tendría sentido porque no se puede acaparar en mercados en los que no existen barreras de entrada ${ }^{31}$. Asimismo, Bullard también afirma que la restricción del segundo párrafo del artículo 61 de la Constitución solo deberá aplicarse y tendrá sentido en mercados en los que existan barreras de entra$\mathrm{da}^{32}$. Sin embargo, el artículo 22 de la LRT es enfático al señalar que la definición de acaparamiento que se utiliza para establecer las cuotas máximas de frecuencias solo aplica a esta ley, quedando abierta la definición de este concepto fuera de la LRT -de conformidad con el fundamento 29 de la sentencia citada-.

Es vital agregar que, si bien el legislador es a quien el TC ha asignado la tarea de reinterpretar el concepto de acaparamiento, esta no puede ser antojadiza. Así pues, es recomendable evitar los cuatro sesgos argumentativos más usuales en los intérpretes de la Constitución: (i) la falacia de origen, (ii) la falacia de reescribir la constitución, (iii) la falacia de desintegración y (iv) la falacia de la hiperintegración ${ }^{33}$. Se incurre en la primera cuando se fundamenta toda la argumentación en el contexto en el que se escribió la disposición constitucional -pues este contexto deberá valorarse como uno más de los elementos a analizar-. Se incide en la segunda la constitución cuando se pretende incorporar conceptos que la Constitución no contiene de modo directo o indirecto. La tercera se comete cuando se fuerza una interpretación aislada de cada disposición constitucional y se evita leerla de forma conjunta. Se cae en la cuarta cuando se pretende establecer vínculos entre disposiciones constitucionales que no pueden o no deben ser leídas en conjunto. Consecuentemente, para efectos de interpretar el artículo 61 de la Constitución y el término acaparamiento consideramos que no es admisible (i) omitir como criterio de valoración el origen de la disposición-cuya fuente es la Constitución de 1979, que tiene un corte en el que predomina lo social a diferencia del corte liberal de la Constitución de 1993-; (ii) incorporar conceptos adicionales a los contenidos en la prohibición del artículo 61; (iii) negar la vinculación entre la prohibición constitucional del artículo 61 y los derechos a la libertad de expresión y a la libertad de información; y (iv) no es admisible circunscribir los fines de la prohibición

28 Ramos, Vania (2013). “Transacciones peligrosas". Puntoedu año 9, $\mathrm{N}^{\circ}$ 287, de 16 al 22 de septiembre, p. 3. Disponible en: <http://files.pucp.edu.pe/puntoedu/wp-content/uploads/2013/09/edu287.pdf> [consulta: 25.05.2015].

29 LANDA, 2016: 352.

30 LANDA, 2016: 354-356

31 Ramos, 2013: 3.

32 Bullard, 2016: 539

33 Tribe, Lawrence y Michael Dorf (2010). Interpretando la Constitución. Lima: Palestra Editores, pp. 39-73. 
del artículo 61 a la protección de la libre competencia solo porque en la Constitución de 1993 se haya optado por introducir ambas disposiciones en un mismo artículo.

Por otro lado, hay juristas que interpretan literalmente ${ }^{34}$ el término acaparamiento como el acto de concentrar bienes escasos. No obstante, esta interpretación supondría que la incorporación de la prensa a la prohibición constitucional se debió a un error material. Asimismo, la llamada interpretación literal haría que la prohibición sea inaplicable en todos los casos de prensa escrita, de radio y de televisión que no usen el espectro radioeléctrico. Por este motivo, consideramos que esta interpretación de acaparamiento es incorrecta porque supondría dejar sin contenido gran parte del mandato constitucional del artículo 61.

Adicionalmente, es imperativo interpretar nuestro derecho interno de conformidad con los instrumentos del Sistema Interamericano de Derechos Humanos (SIDH) al que estamos adscritos ${ }^{35}$. Así, según la Convención Interamericana de Derechos Humanos (CADH), "[n]o se puede restringir el derecho de expresión por vías o medios indirectos, tales como el abuso de controles oficiales o particulares de papel para periódicos, de frecuencias radioeléctricas, o de enseres y aparatos usados en la difusión de información por cualesquiera otros medios encaminados a impedir la comunicación y circulación de ideas y opiniones"36. Inclusive, consideramos pertinente citar uno de los principios recogidos en la Declaración de Principios Sobre Libertad de Expresión:

"12. Los monopolios u oligopolios en la propiedad y control de los medios de comunicación deben estar sujetos a leyes antimonopólicas por cuanto conspiran contra la democracia al restringir la pluralidad y diversidad que asegura el pleno ejercicio del derecho a la información de los ciudadanos. En ningún caso esas leyes deben ser exclusivas para los medios de comunicación. Las asignaciones de radio y televisión deben considerar criterios democráticos que garanticen una igualdad de oportunidades para todos los individuos en el acceso a los mismos" 37 .

Asimismo, la Corte Interamericana de Derechos Humanos (Corte IDH) se ha pronunciado siguiendo esta línea interpretativa en el caso Granier y otros (Radio Caracas Televisión) vs. Venezuela, convirtiendo lo expuesto en mandato aplicable a los Estados adscritos al SIDH. Así pues, mediante la referida sentencia, la Corte IDH ha desarrollado e integrado tres puntos en materia de pluralismo informativo, medios de comunicación, libertad de expresión y democracia ${ }^{38}$ : (i) se consagra el pluralismo como elemento

34 La interpretación literal del término acaparamiento tiene varias acepciones. Si bien la primera es adquirir y retener cosas para prevenir su escasez, la segunda acepción del término según la Real Academia Española es apropiarse u obtener en todo o en gran parte, un género de cosas. Así pues, la segunda acepción se asemeja a lo que entendemos por concentrar.

35 Organización de los Estados Americanos (OEA). Carta Democrática Interamericana, aprobada en la primera sesión plenaria, celebrada el 11 de septiembre de 2001.

36 OEA. Convención Interamericana de Derechos Humanos, dada en San José de Costa Rica el 22 de noviembre de 1969 .

37 Comisión Interamericana de Derechos Humanos. Declaración de Principios Sobre Libertad de Expresión, adoptada en el $108^{\circ}$ período ordinario de sesiones, celebrado el 19 de octubre de 2000.

38 Conte IDH. Caso Granier y otros (Radio Caracas Televisión) vs. Venezuela (excepciones preliminares, fondo, reparaciones y costas). Sentencia de 22 de junio de 2015. Serie C No 293, párr. 141-143. 
Bruno Adriano Delgado Taboada

La concentración de los medios de comunicación y los alcances del segundo párrafo del artículo 61 de la Constitución peruana en la prensa escrita

correlativo de la libertad de expresión y la tolerancia, sin estos no puede existir una sociedad democrática, (ii) se establece que la pluralidad de medios e informativa es una garantía y deber del Estado para permitir el acceso universal y sin discriminación a los medios de comunicación y (iii) se reconoce que la libertad de expresión también puede ser afectada sin intervención estatal o ante la ausencia de esta, cuando por efecto de la existencia de monopolios u oligopolios en los medios de comunicación se configuran mecanismos que impiden la libre circulación de ideas y opiniones. Por último, la Corte IDH, por medio de esta sentencia, determinó que los Estados adscritos al SIDH “están internacionalmente obligados a adoptar las medidas que fueren necesarias 'para hacer efectivos' los derechos y principios establecidos en la Convención, como se estipula en el artículo 2 de dicho instrumento interamericano, para ello deberán establecer leyes y políticas públicas que garanticen el pluralismo de medios o informativo en las distintas áreas comunicacionales, tales como, por ejemplo, la prensa, radio y televisión"39. Consecuentemente, la Corte IDH reconoce literalmente que los Estados están obligados internacionalmente a promover el pluralismo informativo mediante el establecimiento de leyes y políticas públicas en la prensa, radio y televisión.

Siendo conscientes de que estamos ante un vacío legal debido a la insuficiencia del artículo 61 y a la falta de idoneidad de la LRT para optimizar el referido mandato constitucional: ¿Cómo podemos optimizar el cumplimiento del referido mandato constitucional? Pues bien, la respuesta es la que ya esbozó el TC indirectamente: mientras se cumpla con el mandato constitucional ya trazado, el legislador puede optar por diversas fórmulas para la consecución de este fin en mérito al principio de libre configuración legal previsto en el artículo 93 de la Constitución peruana.

\section{Propuesta alternativa de Regulación}

La solución que considero más idónea para regular las concentraciones mediáticas en general, y que, en particular, también resolvería los problemas de las concentraciones en prensa escrita y las concentraciones cruzadas, está inspirada en el sistema de control de fusiones y adquisiciones del Reino Unido.

En el Reino Unido se regulan los controles de fusiones y adquisiciones de una forma muy distinta a la de otros países. Al igual que en la mayoría de países del mundo, mediante el control de fusiones y adquisiciones se busca recolectar data de las empresas fiscalizadas y analizarla para determinar si una fusión o adquisición es lesiva al mercado o a los consumidores, sujetándose a estrictos criterios de mercado que giran en torno a la protección de la libre competencia. Sin embargo, hay un control de fusiones especial, al que se le llama public interest interventions. Estos casos representan supuestos excepcionales en los que no se aplican las normas convencionales vinculadas a la protección de la libre competencia, sino que permiten la intervención del Secretario de Estado en materias vinculadas a seguridad nacional y pública, fusiones de empresas de prensa escrita u otros medios de comunicación y fusiones en las que peligre la estabilidad del sistema financiero ${ }^{40}$. Es importante destacar que los criterios

39 CoRte IDH. Caso Granier y otros vs. Venezuela, párr. 145.

40 Competition \& Markets Authority (2014). Mergers: Guidance on the CMA's jurisdiction and procedure, Editorial de la Corona del Reino Unido, Londres. 
que se utilizan en los supuestos excepcionales mencionados son especiales referidos al interés público que se busca proteger, excluyéndose los criterios vinculados a la libre competencia. En ese sentido, en el caso de las fusiones de empresas de prensa escrita y otros medios de comunicación, el Secretario de Estado no tendrá una intervención arbitraria, sino todo lo contrario: la Competition and Markets Authority evaluará el caso y emitirá un informe basado en criterios de libre competencia y enviará el caso a la Office of Communications que se encargará de desarrollar el llamado public interest test, también conocido como test of plurality. El referido test es un estudio técnico que mide la afectación que tendría la fusión o la adquisición al pluralismo informativo y considerará, entre otras cosas, el porcentaje de información que controlaría la empresa concentradora, las cuotas de mercado que controlaría el concentrador -considerando propiedad cruzada de medios de comunicación- y el control que el grupo económico mantiene sobre la o las empresas vinculadas ${ }^{41}$. De este modo, el Secretario de Estado tendría una decisión informada por un estudio de la CMA y otro estudio de la OFCOM, los que contienen sus respectivas recomendaciones; no obstante, el Secretario de Estado tendrá libertad para ponderar y valorar los aportes de estas entidades en su decisión final $^{42}$-que determinará si procede o no la concentración-.

Ahora bien, el problema con la regulación del Reino Unido está en que, si bien controla las fusiones y adquisiciones de empresas en atención a criterios de interés público como el pluralismo informativo, esta encarga la decisión a una autoridad política como es el Secretario de Estado. La consecuencia de esta fórmula ha sido la abstinencia de la autoridad como regla general, siendo muy pocos los casos que se conocen en que el Secretario de Estado optó por prohibir concentraciones mediáticas (como los casos ${ }^{43}$ Sullivan y Century Newspaper Ltd. - Thompson Regional Group Ltd.).

Por los motivos antes mencionados, consideramos que la forma más idónea de desarrollar el mandato del artículo 61 de la constitución sería aprobar una ley que establezca un control de fusiones y adquisiciones especiales por razones de interés público, inspirado en la regulación del Reino Unido, pero con algunos cambios. Así pues, las empresas de medios de comunicación que opten por realizar operaciones de fusiones o adquisiciones deberían informar previamente de sus intenciones a la autoridad administrativa competente. De este modo, mediante la implementación del control de fusiones y adquisiciones se recolectaría la data suficiente para poder realizar un test de pluralidad que determine si la operación cuestionada es lesiva o no es lesiva al pluralismo informativo y en qué proporción. En función a los resultados del test, la ley debería determinar los remedios aplicables, que podrían ser: la admisión sin condiciones, la admisión con condiciones y la prohibición de la operación. De este modo, la autoridad administrativa a la que se le asigne esta función -que podría ser una autoridad especial

41 Office Of Communications (2004). Ofcom guidance for the public interest test for media mergers Editorial de la Corona del Reino Unido, Londres.

42 Como todo acto administrativo, es susceptible de ser impugnado judicialmente, no obstante, por la forma en la que se configuran las facultades que la normativa le otorga al Secretario de Estado, sería prácticamente imposible que un juez revise cuestiones de fondo respecto de su decisión.

43 LANDA, 2016: 361-362. 
Bruno Adriano Delgado Taboada

La concentración de los medios de comunicación y los alcances del segundo párrafo del artículo 61 de la Constitución peruana en la prensa escrita

de comunicaciones o el mismo INDECOPI ${ }^{44}$ - determinará qué remedio es aplicable al caso concreto, tomando en consideración los resultados del test de pluralidad ${ }^{45}$. La gran diferencia está en que la decisión deberá recaer en una agencia independiente que cuente con mayor legitimidad para realizar este control, independientemente de las presiones que puedan ejercer las entidades reguladas. La misma fórmula regulatoria podría ser aplicable a todos los países de Latinoamérica, por cuanto todos enfrentamos esta misma problemática; no obstante, tanto para su aprobación como implementación exitosa se requerirá voluntad política y respaldo ciudadano.

\section{LA JUDICIALIZACIÓN COMO RESPUESTA AL ACTUAL VACÍO DE LEY}

La solución frente al vacío de ley ante casos de concentración mediática es aprobar regulación que cumpla con optimizar de forma idónea el mandato constitucional. No obstante, esta solución solo alcanzaría a los casos de concentración mediática posteriores a la aprobación de esta normativa -debido a la imposibilidad de aplicación retroactiva de la ley-. Así pues, ¿qué podemos hacer frente a las concentraciones mediáticas que se hubieran dado antes de la aprobación de una nueva ley?

Frente al vacío legal, la única alternativa posible sería la judicialización de la controversia. Esto es exactamente lo ocurrido con el caso de la adquisición de Epensa por parte del grupo El Comercio. Un grupo de ocho periodistas interpuso una demanda de amparo contra el grupo El Comercio por esta adquisición, solicitando que se declare la nulidad de la compra de acciones por implicar una vulneración a la prohibición establecida en el segundo párrafo del artículo 61 de la Constitución y por menoscabar el pluralismo informativo y el derecho a la libertad informativa.

Es claro que el proceso de amparo es una vía idónea y satisfactoria para solucionar las controversias que se generen mientras que no sea posible aprobar una ley que pueda optimizar el mandato del artículo 61 de la Constitución. Ahora bien, ¿si es factible que se proteja el pluralismo informativo mediante la judicialización de estos casos por la vía de amparo, por qué sería necesario aprobar una ley? Esto porque, para estos casos, la judicialización, si bien es la única solución factible, no es la más idónea para garantizar una adecuada protección y promoción del pluralismo informativo. Esto en cuanto a que, de por sí, es muy complicado para un juez constitucional declarar la nulidad de una operación comercial de adquisición o fusión empresarial si hay tan poca claridad y precisión conceptual para estos efectos.

En ese sentido, podemos desprender al menos tres razones por las que la judicialización no sería tan efectiva como una ley que desarrolle el referido mandato constitucional. En primer lugar, la falta de claridad y precisión conceptual podría terminar generando una abstención de parte del juzgador constitucional frente a operaciones de concentración mediática o, lo que es peor, que se efectúen decisiones arbitrarias que no respondan a criterios comunes de interpretación y que generen inseguridad jurídica. En segundo

44 Instituto Nacional de Defensa de la Competencia y la Propiedad Intelectual. Entidad peruana encargada de proteger la libre competencia, la propiedad intelectual y los derechos de los consumidores.

45 Evidentemente, la resolución de la autoridad administrativa podría ser materia de impugnación administrativa y judicial, pero los efectos de su decisión se mantendrían salvo hasta el momento en que se declare su nulidad, de ser el caso. 
lugar, la falta de precisión para determinar remedios frente a las operaciones de concentración de medios podría llevar a los jueces a fallar únicamente declarando la nulidad de las operaciones o su viabilidad y no habría posibilidad de desarrollar soluciones intermedias como admitir la fusión sujeta a ciertos criterios o cumplimiento de condiciones, debido a la falta de información o la falta de capacidad técnica para procesar la información. En tercer lugar, las dificultades antes mencionadas no permitirían a los jueces tener certeza acerca de cuál es la proporción de mercado a cuya operación cabría imponer una prohibición, admisión sujeta a criterios o cumplimiento de condiciones y admisión sin observaciones.

Así, de optar por la judicialización como respuesta definitiva frente al vacío de ley, los jueces controlarán exclusivamente las operaciones de fusiones y adquisiciones en las que el menoscabo del pluralismo informativo sea manifiesto y evidente. Ante este escenario, no alcanzaríamos ni una protección y fomento adecuado del pluralismo informativo ni un escenario de seguridad jurídica.

Por estos motivos, no es constitucionalmente admisible que persistamos en mantener el vacío de ley que existe actualmente ${ }^{46}$. Ahora bien, esto no quiere decir que habrá que abstenernos a utilizar la judicialización como opción. En el caso de la adquisición de Epensa por parte del grupo El Comercio, es viable que el juez constitucional declare la nulidad de la adquisición, en tanto es evidente que la afectación que esta operación tendría contra el pluralismo informativo sería significativa. Con la operación cuestionada del grupo El Comercio pasarían a tener el 75\% del control de la circulación de diarios a nivel nacional y el $83 \%$ a nivel de Lima ${ }^{47}$, por lo que el menoscabo que la operación tendría contra el pluralismo informativo externo es indiscutible. Probablemente, si el control que el grupo El Comercio ejerce en la circulación de diarios a nivel nacional fuera menor, tendríamos muchas mayores dudas respecto de la posibilidad de que el juez constitucional opte por prohibir dicha operación. De todos modos, si bien consideramos que en el caso del grupo El Comercio el juez constitucional debería optar por declarar la nulidad de la operación por los motivos antes señalados, mientras no haya una ley que regule con claridad el mandato del artículo 61 de la Constitución, no podrá haber certeza posible concerniente a lo que finalmente determine el juez constitucional que corresponde fallar en casos como el presente.

\footnotetext{
46 Respecto al rol asignado a la justicia constitucional en el Perú, cabe decir que la discusión ha sido resuelta por el Código Procesal Constitucional (Ley N ${ }^{\circ}$ 28237), que en su artículo II del Título Preliminar establece que los fines de los procesos constitucionales son: (i) garantizar la supremacía de la Constitución (desde una perspectiva objetiva de defensa del ordenamiento constitucional) y (ii) la vigencia efectiva de los derechos constitucionales (desde una perspectiva subjetiva de defensa de derechos). Así, en el caso de la protección del pluralismo informativo, tanto el legislador como el juez constitucional tendrían competencia desde ámbitos distintos. El legislador deberá desarrollar los mandatos contenidos en el artículo $61^{\circ}$ de la Constitución a través de la emisión de leyes idóneas, mientras que el juez constitucional deberá resolver los recursos planteados en defensa del derecho fundamental a la libertad de información (que incluye el pluralismo informativo), reconocido en el artículo $2^{\circ}$, inciso 4 de la Constitución. En ese sentido, no estamos ante ámbitos reservados, la discusión es más bien de índole práctica: ¿cómo se protege de forma más eficaz el pluralismo informativo?

47 Fernández, José (2014). Estudio de la estructura del mercado de la prensa escrita en el Perú. Lima: Centro de Investigación de la Universidad del Pacífico. Disponible en: <http://srvnetappseg.up.edu.pe/siswebciup/ Files/DD1401_Fernenadez\%20Baca.pdf>. [Consulta: 18.05.2015].
} 
Bruno Adriano Delgado Taboada

La concentración de los medios de comunicación y los alcances del segundo párrafo del artículo 61 de la Constitución peruana en la prensa escrita

Sea la opción legislativa que se adopte, la determinación legal de los supuestos y remedios aplicables para la protección y promoción del pluralismo informativo nos permitirán aproximarnos un poco más al ideal constitucional de una sociedad democrática en la que la formación de una opinión pública libre sea la base de una ciudadanía que conoce y ejerce sus derechos.

\section{Conclusión}

Con el presente artículo hemos abordado la problemática de la concentración de los medios de comunicación respecto del menoscabo que esta produce en el pluralismo informativo. Para efectos de comprender el impacto de estas concentraciones en el pluralismo informativo, hemos reconocido dos dimensiones del mismo: interna y externa. El reconocimiento de ambas dimensiones, a su vez, informa el contenido de las obligaciones que son exigibles a los Estados respecto del pluralismo informativo: (i) establecer controles democráticos de las concentraciones de los medios de comunicación para promover la pluralidad de medios y para evitar el control de la agenda pública y (ii) promover la pluralidad de contenidos, información y opiniones al interior de los medios de comunicación.

Asimismo, hemos analizado los alcances del segundo párrafo del artículo $61^{\circ}$ de la Constitución peruana respecto de la concentración de la prensa escrita. En ese sentido, hemos concluido que, de conformidad con los instrumentos del SIDH y con la jurisprudencia de la Corte IDH, el segundo párrafo del artículo $61^{\circ}$ de la Constitución peruana establece un mandato de promoción y protección del pluralismo informativo que incluye la obligación de desarrollar leyes y políticas públicas que harían efectivo el contenido de la referida disposición constitucional en la prensa, radio, televisión y demás medios de comunicación social, independientemente de si dependen de la operación del espacio radioeléctrico o no. No obstante, hemos concluido que, a pesar de la existencia del mandato constitucional referido, nos encontramos frente a un vacío legal respecto de las concentraciones de propiedad cruzada, de prensa escrita y de medios que no dependen del espacio radioeléctrico.

Frente al vacío legal, hemos propuesto como opción legislativa la creación de un control de fusiones y adquisiciones especiales por razones de interés público, inspirado en el sistema del Reino Unido, pero con ligeros cambios. Entre estos, podemos destacar que la decisión de prohibir la concentración o admitirla con o sin condiciones debería recaer sobre una agencia regulatoria independiente. Proponemos esta fórmula regulatoria para todos los países de Latinoamérica, por cuanto todos enfrentamos esta misma problemática; no obstante, tanto para su aprobación como implementación exitosa se requerirá voluntad política y respaldo ciudadano.

Finalmente, hemos aportado nuestras razones acerca del porqué la aprobación de una ley especial sería más idónea que la judicialización de las controversias para efectos de promover y proteger el pluralismo informativo. No obstante, hacemos énfasis en que la judicialización, sea por medio de la vía constitucional o del litigio ante la Corte IDH, no deberá ser descartada, por cuanto es la única solución aplicable mientras que no se establezcan leyes idóneas para efectos de promover y proteger el pluralismo informativo. 


\section{Bibliografía}

Beaumont Callirgos, Ricardo (2013). "Monopolios y medios de comunicación social". En: Chanamé, Raúl (ed.), La Constitución Comentada. Tomo II, Lima: Editorial Gaceta Jurídica, pp. 98-103.

Bullard, Alfredo (2016). "Sentencia Previa: Concentración de medios, competencia económica y libertad de expresión”. En: KRESALJA, Baldo y David Lovatón (coords.). ¿Puede acapararse la libertad? Libertad de expresión y concentración de medios en el Perú. Lima: Oficina Académica de Publicaciones, Comunicación e Imagen de la Facultad de Derecho de la Pontificia Universidad Católica del Perú, pp. 501-573.

(2013). "Regulación constitucional de los monopolios y protección de la Libre Competencia”. En: Chanamé, Raúl (ed.), La Constitución Comentada. Tomo II, Lima: Editorial Gaceta Jurídica, pp. 69-87.

Dodds Berger, Daniel (2011). "Concentración de medios y libertad de comunicación. Un análisis jurídico-constitucional”. Repositorio Académico de la Universidad de Chile. Disponible en: <http://www.repositorio.uchile.cl/handle/2250/111866> [consulta: 25.05.2015].

FARFÁn, Ronnie (2014). "La prohibición constitucional de concentración de la propiedad de los medios de comunicación”. Revista de Derecho Administrativo (14): 341-362.

FERnández, José (2014). Estudio de la estructura del mercado de la prensa escrita en el Perú. Lima: Centro de Investigación de la Universidad del Pacífico. Disponible en: <http://srvnetappseg.up.edu.pe/siswebciup/Files/DD1401_Fernenadez\%20Baca. pdf $>$ [consulta: 18.05.2015].

Gómez, Alberto (2002). El control de las concentraciones de medios de comunicación. Madrid: Editorial Dykinson.

Kresalja, Baldo (2016). "Nadie puede negar". En: Kresalja, Baldo y David Lovatón (coords.). ¿Puede acapararse la libertad? Libertad de expresión y concentración de medios en el Perú. Lima: Oficina Académica de Publicaciones, Comunicación e Imagen de la Facultad de Derecho de la Pontificia Universidad Católica del Perú.

LANDA, César (2015). La inconstitucionalidad de la concentración de la prensa escrita [en línea]. Lima: Portal Jurídico IUS $360^{\circ}$. Disponible en: <http://www.ius360.com/ publico/constitucional/la-inconstitucionalidad-de-la-concentracion-de-la-prensa-escrita/> [consulta: 15.05.2015].

(2016). "El artículo 61 de la Constitución y la concentración de los medios de comunicación”. En: KresaLJa, Baldo y David Lovatón (coords.). ¿Puede acapararse la libertad? Libertad de expresión y concentración de medios en el Perú. Lima: Oficina Académica de Publicaciones, Comunicación e Imagen de la Facultad de Derecho de la Pontificia Universidad Católica del Perú, pp. 341-375.

LLAMAZARES, María (1999). Las libertades de expresión e información como garantía del pluralismo democrático. Madrid: Editorial Civitas Ediciones.

Lovatón Palacios, David (2014). "El equilibrio interamericano entre la pluralidad de información y concentración de medios". Revista Derecho PUCP (73): 131-153. 
Bruno Adriano Delgado Taboada

La concentración de los medios de comunicación y los alcances del segundo párrafo del artículo 61 de la Constitución peruana en la prensa escrita

(2016). "Estándares interamericanos sobre pluralidad de información y concentración de medios". En: Kresalua, Baldo y David Lovatón (coords.). ¿Puede acapararse la libertad? Libertad de expresión y concentración de medios en el Perú. Lima: Oficina Académica de Publicaciones, Comunicación e Imagen de la Facultad de Derecho de la Pontificia Universidad Católica del Perú.

Northcote Sandoval, Cristhian (2014). "La supuesta concentración de medios en la prensa escrita". Revista Actualidad Empresarial (294): 1-4. Disponible en: <http:// aempresarial.com/servicios/revista/294_43_OUYGHCWQSUHXCBZNUSGFVLF DQQRZDJIREGXLJTCCOKZQLYEGQK.pdf> [consulta: 25.05.2015].

RAllo, Artemi (2000). Pluralismo informativo y constitución. Valencia: Editorial Tirant lo Blanch.

Ramos, Vania (2013). "Transacciones peligrosas". Puntoedu año 9, No 287, de 16 al 22 de septiembre. Disponible en: <http://files.pucp.edu.pe/puntoedu/wp-content/ uploads/2013/09/edu287.pdf> [consulta: 25.05.2015].

Rodríguez, José (1998). El control de los medios de comunicación. Madrid: Editorial Dykinson.

RoJAs, Juan Francisco (2013). "Promoción de la competencia y prohibición de monopolios”. En: Chanamé, Raúl (ed.). La Constitución Comentada. Tomo II, Lima: Editorial Gaceta Jurídica.

Rubio, Marcial (2015). Para conocer la Constitución de 1993. Lima: Fondo Editorial PUCP.

Rubio, Marcial y Enrique Bernales (1983). Constitución y sociedad política. Lima: Editorial Mesa Redonda.

Ruiz-Eldredge, Alberto (1980). La Constitución comentada 1979. Lima: Editorial Atlántida.

TÁvara, José (2016). “Economía Política de la concentración de los medios”. En: Kresalja, Baldo y David Lovatón (coords.). ¿Puede acapararse la libertad? Libertad de expresión y concentración de medios en el Perú. Lima: Oficina Académica de Publicaciones, Comunicación e Imagen de la Facultad de Derecho de la Pontificia Universidad Católica del Perú.

TAvera, José (2014). “Acerca de la concentración de la propiedad de los medios de comunicación”. Lima: Portal Jurídico IUS 360. Disponible en: <http://www.ius360. com/publico/administrativo/acerca-de-las-concentracion-de-propiedad-en-los-mediosde-comunicacion/> [consulta: 25.05.2015].

Tribe, Lawrence y Michael Dorf (2010). Interpretando la Constitución. Lima: Palestra Editores, pp. 39-73.

ZúÑIgA, Francisco (2008). "Propiedad y control de los medios de comunicación social: algunas notas sobre el estatuto de radiodifusión”. Revista Estudios Constitucionales 6(1): 171-203.

ZukERnik, Eduardo (2008). Observador de medios de comunicación en América Latina: prensa, ciudadanía y democracia en Brasil, Colombia, Ecuador, Perú y Venezuela. Primera edición. Buenos Aires: Konrad Adenauer Stiftung. 


\section{LEGISLACIÓN}

Constitución Política del Perú de 1979. Asamblea Constituyente de la República del Perú, 13 de agosto de 1980.

Constitución Política del Perú de 1993. Congreso Constituyente Democrático de la República del Perú, 30 de diciembre de 1993.

Ley N $\mathrm{N}^{\circ}$ 28094, que aprueba la Ley de Partidos Políticos. Congreso de la República del Perú, 1 de noviembre de 2003.

Ley N ${ }^{\circ}$ 28237, que aprueba el Código Procesal Constitucional. Congreso de la República del Perú, 31 de mayo de 2004.

Ley $\mathrm{N}^{\circ} 28278$, que aprueba la Ley de Radio y Televisión. Congreso de la República del Perú, 16 de julio de 2004.

\section{JURISPRUDENCIA}

Corte IDH. Caso Granier y otros (Radio Caracas Televisión) vs. Venezuela (excepciones preliminares, fondo, reparaciones y costas). Sentencia de 22 de junio de 2015. Serie C N 293.

Tribunal Constitucional de la República del Perú. Sentencia recaída en el Expediente No 00013-2007-AI/TC. Sentencia de 13 de julio de 2007.

Sentencia recaída en el Expediente $\mathrm{N}^{\circ}$ 00015-2010-AI/TC. Sentencia de 11 de setiembre de 2012 .

\section{OTROS TEXTOS INTERNACIONALES}

Comisión Interamericana de Derechos Humanos. Declaración de Principios Sobre Libertad de Expresión, adoptada en el $108^{\circ}$ período ordinario de sesiones, celebrado el 19 de octubre de 2000.

OEA. Organización de los Estados Americanos. Convención Interamericana de Derechos Humanos, dada en San José de Costa Rica el 22 de noviembre de 1969.

Carta Democrática Interamericana, aprobada en la primera sesión plenaria, celebrada el 11 de septiembre de 2001.

Competition \& Markets Authority (2014). Mergers: Guidance on the CMA's jurisdiction and procedure. Editorial de la Corona del Reino Unido, Londres.

Office Of Communications (2004). Ofcom guidance for the public interest test for media mergers. Editorial de la Corona del Reino Unido, Londres.

Recibido: 9 de marzo de 2016

Aceptado: 10 de junio de 2016 